ORIGINAL ARTICLE

\section{Complement C3 Variant and the Risk of Age-Related Macular Degeneration}

\author{
John R.W. Yates, F.R.C.P., Tiina Sepp, Ph.D., Baljinder K. Matharu, M.Sc., \\ Jane C. Khan, F.R.C.Ophth., Deborah A. Thurlby, R.G.N., M.Sc., \\ Humma Shahid, M.R.C.Ophth., David G. Clayton, M.A., \\ Caroline Hayward, Ph.D., Joanne Morgan, B.Sc., Alan F. Wright, Ph.D., F.R.C.P., \\ Ana Maria Armbrecht, Ph.D., F.R.C.S., Baljean Dhillon, F.R.C.S., F.R.C.Ophth., \\ Ian J. Deary, Ph.D., F.R.C.P.E., Elizabeth Redmond, R.G.N., M.Sc., \\ Alan C. Bird, M.D., F.R.C.S., and Anthony T. Moore, F.R.C.S., F.R.C.Ophth., \\ for the Genetic Factors in AMD Study Group**
}

ABSTRACT

\section{BACKGROUND}

Age-related macular degeneration is the most common cause of blindness in Western populations. Susceptibility is influenced by age and by genetic and environmental factors. Complement activation is implicated in the pathogenesis.

\section{METHODS}

We tested for an association between age-related macular degeneration and 13 singlenucleotide polymorphisms (SNPs) spanning the complement genes $\mathrm{C3}$ and $\mathrm{C5}$ in case subjects and control subjects from the southeastern region of England. All subjects were examined by an ophthalmologist and had independent grading of fundus photographs to confirm their disease status. To test for replication of the most significant findings, we genotyped a set of Scottish cases and controls.

\section{RESULTS}

The common functional polymorphism rs2230199 (Arg80Gly) in the C3 gene, corresponding to the electrophoretic variants C3S (slow) and C3F (fast), was strongly associated with age-related macular degeneration in both the English group (603 cases and 350 controls, $\left.\mathrm{P}=5.9 \times 10^{-5}\right)$ and the Scottish group (244 cases and 351 controls, $\mathrm{P}=5.0 \times 10^{-5}$ ). The odds ratio for age-related macular degeneration in $\mathrm{C} 3$ $\mathrm{S} / \mathrm{F}$ heterozygotes as compared with S/S homozygotes was 1.7 (95\% confidence interval [CI], 1.3 to 2.1); for F/F homozygotes, the odds ratio was 2.6 (95\% CI, 1.6 to 4.1). The estimated population attributable risk for $\mathrm{C} 3 \mathrm{~F}$ was $22 \%$.

\section{CONCLUSIONS}

Complement $\mathrm{C} 3$ is important in the pathogenesis of age-related macular degeneration. This finding further underscores the influence of the complement pathway in the pathogenesis of this disease.
From the Cambridge Institute for Medical Research, University of Cambridge, Cambridge (J.R.W.Y., T.S., B.K.M., J.C.K., D.A.T., H.S., D.G.C.); the Medical Research Council Human Genetics Unit, Edinburgh (C.H., J.M., A.F.W.); the Princess Alexandra Eye Pavilion, Edinburgh (A.M.A., B.D.); the University of Edinburgh, Edinburgh (I.J.D.); the Institute of Ophthalmology, University College London (E.R., A.C.B., A.T.M.); and Moorfields Eye Hospital, London (A.C.B., A.T.M.) - all in the United Kingdom. Address reprint requests to Dr. Yates at the Department of Medical Genetics, University of Cambridge, Cambridge Institute for Medical Research, Wellcome Trust/MRC Bldg., Box 139, Addenbrooke's Hospital, Cambridge CB2 OXY, United Kingdom, or at jrwyl@cam. ac.uk.

Drs. Yates and Sepp contributed equally to this article.

* Other members of the Genetic Factors in Age-Related Macular Degeneration (AMD) Study Group are listed in the Appendix.

This article (10.1056/NEJMoa072618) was published at www.nejm.org on July 18, 2007.

N Engl J Med 2007;357:553-61. Copyright (c) 2007 Massachusetts Medical Society. 
GE-RELATED MACULAR DEGENERATION is the leading cause of visual impairment in the elderly and the most common cause of blindness in Western countries. ${ }^{1}$ It affects the macular region of the retina. The macula has a high density of photoreceptors and provides detailed central vision. In the early stages of the disease (referred to as age-related maculopathy), deposits called drusen develop between the retinal pigment epithelium and underlying choroid. ${ }^{1}$ Later, the disease is manifested as either extensive atrophy of the retinal pigment epithelium and overlying photoreceptor cells (geographic atrophy) or aberrant choroidal angiogenesis (choroidal neovascularization). ${ }^{1}$ Both of these conditions can lead to a loss of central vision. The pathogenesis of age-related macular degeneration is poorly understood. As with other late-onset chronic diseases, susceptibility is influenced by age, ethnic background, and a combination of environmental and genetic factors., ${ }^{1,2}$ Smoking status and family history are well-established determinants of risk. ${ }^{1,2}$

Recently, polymorphisms in the genes coding for complement factor $\mathrm{H}(\mathrm{CFH})$ and complement factor $\mathrm{B}(\mathrm{CFB})$ have been shown to be predictors of risk for age-related macular degeneration. ${ }^{3-11}$ Another susceptibility locus has been mapped to chromosome 10q26; the causative variation probably lies in a hypothetical gene called LOC387715 or in the promoter of the neighboring gene HTRA1. ${ }^{11-14}$ The population attributable risk associated with variants in CFH, CFB, and LOC387715/ HTRA1 is at least $50 \% .{ }^{11}$

$\mathrm{CFH}$ and $\mathrm{CFB}$ are key components of the alternative complement pathway. Their involvement in age-related macular degeneration, together with the finding that drusen contain proteins associated with inflammation and immune-mediated processes, ${ }^{15}$ supports the hypothesis that inflammation and complement activation influence the pathogenesis of age-related macular degeneration. To test whether variants in other genes encoding proteins in the complement pathway influence susceptibility to age-related macular degeneration, we genotyped single-nucleotide polymorphisms (SNPs) spanning the complement genes $\mathrm{C} 3$ and $\mathrm{C5}$, encoding central proteins in the complement cascade, in subjects with age-related macular degeneration and in control subjects.

\section{METHODS}

\section{CASES AND CONTROLS}

We studied three case-control groups, two in England and one in Scotland. English group 1 comprised 446 case subjects with end-stage age-related macular degeneration (geographic atrophy or choroidal neovascularization) and 267 control subjects, who were spouses of the index patients. All subjects were recruited from ophthalmic clinics in eight hospitals in southeastern England from 2002 to $2004 .^{7}$ English group 2 comprised 157 case subjects with end-stage age-related macular degeneration and 83 controls (67 spouses and 16 friends of index patients) recruited from 2003 to 2005, the majority from Moorfields Eye Hospital in London and the remainder from southeastern England. All subjects described themselves as "white" rather than "other" on a recruitment questionnaire.

The Scottish group comprised 505 case subjects with age-related maculopathy or end-stage age-related macular degeneration and 351 control subjects. A total of 337 case subjects from the Lothian region were recruited from ophthalmic clinics in Edinburgh and 46 case subjects from hospitals in Dundee and Inverness from 2004 to 2006. Control subjects, who were recruited from the same sources in similar proportions, comprised 32 spouses and 174 subjects who had undergone cataract surgery. Another 122 case subjects and 145 controls came from the 1921 Lothian birth cohort. ${ }^{16}$

Written informed consent was obtained from all subjects. The research protocol was in keeping with the provisions of the Declaration of Helsinki, and approval was obtained from a multicenter research ethics committee and from research ethics committees for each institution. Subjects were examined by an ophthalmologist, and data were collected regarding medical history, lifestyle, and smoking history. Color, stereoscopic fundus photography of the macular region was performed in all subjects. For English subjects, the images were graded at the Reading Centre, Moorfields Eye Hospital, with the use of the International Classification of Age-Related Maculopathy and Macular Degeneration. ${ }^{17}$ For Scottish subjects, a study investigator graded images; for validation, images from 100 case subjects and 
controls were independently graded at the Moorfields Reading Centre (kappa statistic, 0.84). Eight prospective English controls with age-related macular degeneration and 60 prospective Scottish controls with age-related maculopathy were reclassified as case subjects. Data on disease status, sex, age, and smoking history of subjects are provided in Table 1.

\section{GENOTYPING}

We extracted genomic DNA from peripheralblood leukocytes. We selected SNPs spanning the C3 and C5 genes from the International HapMap Project $^{18}$ data (release 19) for the Centre d'Étude du Polymorphisme Humain (CEPH) population (Utah residents with ancestry from northern and western Europe). Criteria for the selection of SNPs were high heterozygosity with a minor allele frequency of at least 10\%, tagging of the most common haplotypes, and coverage of the main blocks of linkage disequilibrium. The C3 SNP rs2230199 - which is predicted to result in a substitution of a glycine residue for arginine at position 80 (Arg80Gly) - generates the "fast" electrophoretic allotype of $\mathrm{C3}$ (called C3F); the alternative allotype is "slow" (C3S). ${ }^{19,20}$ We included this SNP in the analysis to provide extra coverage and because of evidence of a functional difference between the two alleles. On the basis of our initial analysis, we included rs1047286 (Pro292Leu), which has a known association with rs2230199. ${ }^{20,21}$ Initial genotyping was carried out in English group 1. Markers of interest were genotyped in group 2 when samples became available. Data from the Scottish group were used for replication.

We performed genotyping in English subjects with the use of a single-nucleotide primer extension assay (ABI Prism SNaPshot Multiplex Kit, Applied Biosystems) and a genetic analyzer (ABI

\begin{tabular}{|c|c|c|c|c|}
\hline \multirow[t]{2}{*}{ Variable } & \multicolumn{2}{|c|}{ English Subjects (Groups 1 and 2) } & \multicolumn{2}{|c|}{ Scottish Subjects } \\
\hline & $\begin{array}{l}\text { Controls } \\
(\mathrm{N}=350)\end{array}$ & $\begin{array}{l}\text { Case Subjects } \\
\qquad(\mathrm{N}=603)\end{array}$ & $\begin{array}{l}\text { Controls } \\
(\mathrm{N}=351)\end{array}$ & $\begin{array}{l}\text { Case Subjects } \\
\quad(\mathrm{N}=505)\end{array}$ \\
\hline \multicolumn{5}{|l|}{ Disease status - no. } \\
\hline Age-related maculopathy & & 0 & & 261 \\
\hline Geographic atrophy & & 143 & & 55 \\
\hline Choroidal neovascularization & & 369 & & 189 \\
\hline $\begin{array}{l}\text { Geographic atrophy and choroidal } \\
\text { neovascularization }\end{array}$ & & 91 & & 0 \\
\hline \multicolumn{5}{|l|}{ Sex-no. (\%) } \\
\hline Male & $151(43)$ & $270(45)$ & $152(43)$ & $190(38)$ \\
\hline Female & $199(57)$ & $333(55)$ & $199(57)$ & $315(62)$ \\
\hline Mean age - yri & $75.3 \pm 7.8$ & $79.4 \pm 7.2$ & $78.0 \pm 8.5$ & $77.8 \pm 9.2$ \\
\hline \multicolumn{5}{|l|}{ Smoking history — no. (\%) } \\
\hline No. of subjects & 347 & 595 & 347 & 499 \\
\hline Never smoked & $141(41)$ & $214(36)$ & $161(46)$ & $240(48)$ \\
\hline Current or former smoker & $206(59)$ & $381(64)$ & $186(54)$ & $259(52)$ \\
\hline \multicolumn{5}{|l|}{ Quantity of cigarettes smoked $\uparrow$} \\
\hline 0 pack-yr & $141(41)$ & $214(36)$ & & \\
\hline 0.1-20.0 pack-yr & $126(36)$ & $166(28)$ & & \\
\hline 20.1-40.0 pack-yr & $61(18)$ & $136(23)$ & & \\
\hline$>40.0$ pack-yr & $19(5)$ & $79(13)$ & & \\
\hline
\end{tabular}

* Plus-minus values are means \pm SD.

$\dagger$ For the English subjects, $\mathrm{P}<0.001$ for the comparisons between case and control subjects. Data on the quantity of cigarettes smoked were not collected for the Scottish subjects. 
Prism 3100, Applied Biosystems) and in Scottish subjects - for rs2230199 and rs1047286 — with the use of competitive allele-specific polymerasechain-reaction assays (Taqman SNP Genotyping Assay, Applied Biosystems and KASPar SNP Genotyping System, KBiosciences, respectively). Manufacturers' protocols were followed.

\section{STATISTICAL ANALYSIS}

We used the chi-square test for comparisons of categorical variables and allele and genotype frequencies and to check for Hardy-Weinberg equilibrium. All $\mathrm{P}$ values were calculated with two-sided tests, and no correction was made for multiple testing. The Mann-Whitney $U$ test was used to compare the ages of case subjects and controls. Logistic-regression analysis was used to investigate interactions between genotype and other variables and to estimate odds ratios and $95 \%$ confidence intervals. The covariables of age and smoking history were included in the logistic model if univariate analysis had shown a significant difference. Odds ratios for categorical variables were estimated in relation to a reference category. Data were analyzed with the use of the SPSS statistical software package, version 11.0.

The population attributable risk was calculated from the formula $100 \mathrm{D} \div(1+\mathrm{D})$, in which $D$ was equal to $P_{1}\left(R R_{1}-1\right)+P_{2}\left(R R_{2}-1\right)$, where $P_{1}$ and $\mathrm{P}_{2}$ are the frequencies of the at-risk genotypes, and $R R_{1}$ and $R R_{2}$ their associated relative risks, as compared with the low-risk genotype. For the purposes of estimation, odds ratios were equated to relative risks, since the disease prevalence is low.

\section{RESULTS}

In the initial screening, 12 SNPs spanning C3 and $C 5$ (those listed in Table 2, excluding rs1047286) were genotyped in 446 case subjects with late-stage age-related macular degeneration and 267 control subjects (English group 1). No evidence of an association was found with variants in $C 5$ (Table 2). In C3, the expressed SNP rs2230199 showed strong evidence of an association $(\mathrm{P}<0.001)$ and was genotyped in an additional 157 case subjects and 83 controls (English group 2). The enlarged sample also provided strong evidence of an association $\left(\mathrm{P}=5.9 \times 10^{-5}\right)$ (Table 2).

To test for replication of this finding, rs2230199 was genotyped by a different laboratory in 244 case subjects with late-stage age-related macular degeneration, 261 case subjects with age-related maculopathy, and 351 controls (Scottish group). Again, there was a highly significant association between the minor allele and age-related macular degeneration $\left(\mathrm{P}=5.0 \times 10^{-5}\right)$ (Table 3). International HapMap Project ${ }^{18}$ data for the CEPH population showed that rs2230199 had an $\mathrm{r}^{2}$ value of 0.75 with rs2230203 but a low $\mathrm{r}^{2}$ value with other C3 SNPs in our marker panel and with other $C 3$ SNPs in the HapMap data set. SNP rs2230203 did not show a significant association with agerelated macular degeneration in group 1 alone, but there was weak evidence of an association in groups 1 and 2 combined (Table 2).

Because of the known association between the allotypes of rs2230199 and the expressed C3 SNP rs1047286, the English and Scottish subjects were genotyped for this marker (Tables 2 and 3). The minor allele frequency was significantly higher in case subjects than in controls in both groups, but the association was not as strong as for rs2230199. Stepwise logistic-regression analysis confirmed that rs2230199 is a significantly better predictor of risk for age-related macular degeneration. With this SNP in the model, adding rs1047286 made no contribution ( $\mathrm{P}=0.90)$. With rs1047286 in the model, adding rs2230199 produced a significant improvement in fit $(\mathrm{P}=0.02)$.

Odds ratios for age-related macular degeneration as a function of rs2230199 genotype are given in Table 4. Results for the English and Scottish groups were similar. In the combined data set, with the common CC genotype as the reference, the odds ratio was 1.7 for CG heterozygotes and 2.6 for GG homozygotes. The estimated population attributable risk for this variant was $22 \%$.

Subgroup analysis that was confined to case subjects with only choroidal neovascularization showed a highly significant association in both case-control groups. For case subjects with only geographic atrophy, the association was significant in the English group $\left(\mathrm{P}=4.6 \times 10^{-4}\right)$ but not in the Scottish group, which had fewer subjects with geographic atrophy. The Scottish group included case subjects with age-related maculopathy, and in this subgroup the association fell just short of significance (Table 3).

Data on other susceptibility loci for age-related macular degeneration were available for English group 1. Results for $\mathrm{CFH} \mathrm{Y} 402 \mathrm{H}$ have been pub- 


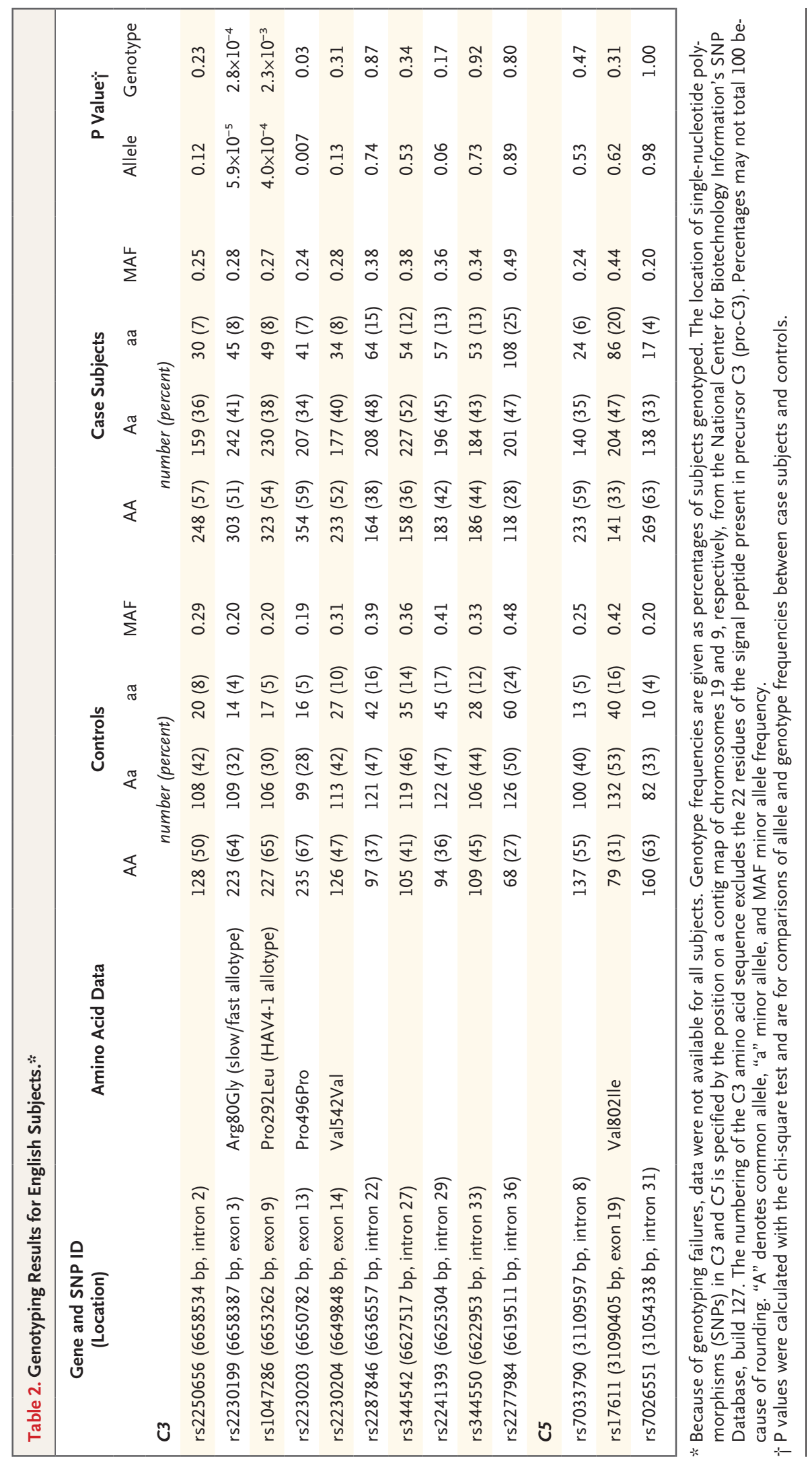




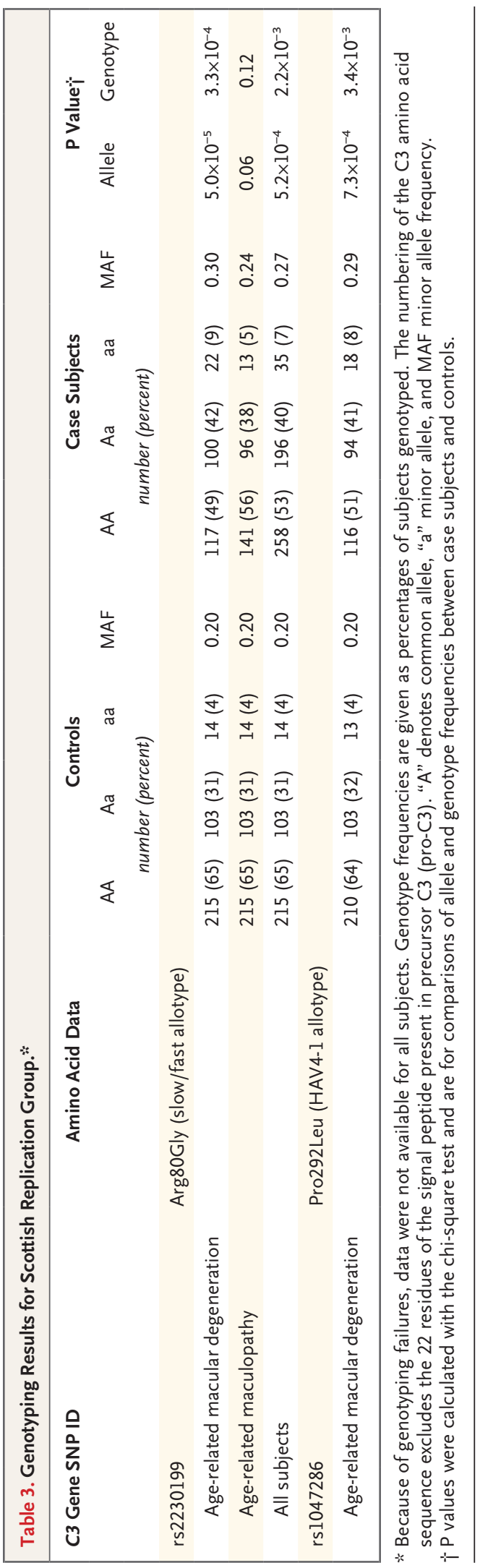

lished previously and are in agreement with other reports. ${ }^{7}$ Odds ratios and population attributable risks for LOC387715 (rs10490924) and CFB (rs641153) are given in Table 5 . The results are similar to those of other studies, except that we found a lower odds ratio for rs10490924 homozygotes. When these variables were included in the stepwise logistic model, C3 rs2230199 remained significant, with an odds ratio of 1.4 for CG heterozygotes and 3.3 for GG homozygotes (with CC genotype as the reference), confirming that these susceptibility loci are independent risk factors.

\section{DISCUSSION}

Our study showed a strong association between the complement C3 S/F (Arg80Gly) polymorphism and age-related macular degeneration, with similar findings for geographic atrophy and choroidal neovascularization. The C3F allele frequency is approximately $20 \%$ in white populations but lower in other ethnic groups. For age-related maculopathy, the association fell just short of significance, raising the possibility that this polymorphism has less influence on the earlier stages of the disease.

The complement system comprises more than 30 plasma and cell-surface proteins. It mediates the host defense against pathogens and the elimination of immune complexes and apoptotic cells; it also facilitates adaptive immune responses. ${ }^{22}$ $\mathrm{C} 3$ is the most abundant complement component, synthesized predominantly in the liver but to a lesser extent in other cells and tissues. Significant C3 messenger RNA is detectable in the neural retina, choroid, retinal pigment epithelium, and cultured retinal-pigment-epithelium cells. ${ }^{15}$

Cleavage of C3 into C3a and C3b is the central step in complement activation and can be initiated by the classic antibody-mediated pathway, the lectin pathway, or the alternative complement pathway. ${ }^{22} \mathrm{C} 3 \mathrm{~b}$ attaches to pathogens or other target surfaces and binds factor $\mathrm{B}$, which is then cleaved. The resulting C3bBb complex has C3 convertase activity, which amplifies the response by further cleavage of $\mathrm{C} 3$ and leads to the formation of $\mathrm{C}_{3} \mathrm{~b}_{2} \mathrm{Bb}$ complexes with $\mathrm{C} 5$ convertase activity. This brings about cleavage of component $\mathrm{C} 5$ and recruitment by $\mathrm{C} 5 \mathrm{~b}$ of components $\mathrm{C} 6$ through $\mathrm{C} 9$ to form a large molecular pore on target membranes (the membrane attack complex), resulting in cell lysis. ${ }^{22}$ 
Drusen contain C3 and its activation products, as well as $\mathrm{C} 5$, membrane attack complex, and $\mathrm{CFH},{ }^{6,15}$ supporting the hypothesis that local inflammation and activation of the complement cascade contribute to the pathogenesis of age-related macular degeneration. Further support for this hypothesis comes from conclusive evidence that variants in $\mathrm{CFH}$ influence susceptibility to age-related macular degeneration..$^{3-9}$ $\mathrm{CFH}$ is a key regulator of the alternative complement pathway and prevents uncontrolled complement activation. Variants in factor B also appear to influence susceptibility to age-related macular degeneration. ${ }^{10,11}$ In mice, activation of complement and formation of the membrane attack complex are essential for the development of laser-induced choroidal neovascularization. Indeed, the finding that choroidal neovascularization cannot be induced by laser coagulation in $\mathrm{C}^{-1-}$ mice demonstrates the key role of $\mathrm{C} 3$ in this process. ${ }^{23}$

As a result of cleavage of $\mathrm{C} 3$ to form $\mathrm{C} 3 \mathrm{~b}$, the molecule undergoes conformational changes that expose several binding sites, including the thioester moiety, which is essential for C3b binding to target surfaces. ${ }^{24}$ Exposure of this activated acyl-imidazole intermediate requires a substantial relocation of the thioester-containing domain to a position adjacent to the first macroglobulin domain. ${ }^{24}$ Arg80 together with Arg72 and Lys82 forms a positively charged patch on the surface of this domain, which, in C3b, is brought into close proximity with the negatively charged carboxyl groups of several amino acids on the surface of the thioester-containing domain (Fig. 1). Substitution of an uncharged glycine for the positively charged Arg80 is predicted to weaken the interaction between these oppositely charged surfaces and could potentially influence thioester activity or other binding interactions of the thioester-containing domain, including a probable $\mathrm{C} 3 \mathrm{~b} / \mathrm{C} 3 \mathrm{~d}$ binding site with $\mathrm{CFH} .{ }^{25}$ It follows that there could well be functional differences between the $\mathrm{C} 3 \mathrm{~S} / \mathrm{F}$ variants.

Direct experimental evidence of functional differences in vitro between the $\mathrm{C} 3 \mathrm{~S} / \mathrm{F}$ allotypes is not conclusive. Arvilommi ${ }^{26}$ reported that erythrocytes coated with $\mathrm{C} 3 \mathrm{~F}$ showed greater rosetting with peripheral-blood mononuclear cells than those coated with C3S. Welch et al. ${ }^{27}$ studied uptake on sheep erythrocytes, hemolytic activity, conversion to inactive $\mathrm{C} 3 \mathrm{~b}$, and capacity to solu-
Table 4. Complement C3 rs2230199 Genotype (C3 S/F Allotype) and Odds Ratios for Age-Related Macular Degeneration.*

\begin{tabular}{lcc|} 
Group & \multicolumn{2}{c|}{ Odds Ratio (95\% CI) } \\
& CG (C3 S/F Allotype) & GG (C3 F/F Allotype) \\
English subjects & $1.6(1.2-2.2)$ & $2.4(1.3-4.4)$ \\
Scottish subjects & $1.8(1.2-2.6)$ & $2.9(1.4-5.9)$ \\
Combined groups & $1.7(1.3-2.1)$ & $2.6(1.6-4.1)$ \\
\hline
\end{tabular}

* Odds ratios are for the comparison with the CC genotype (C3 S/S allotype).

Table 5. Odds Ratios for Age-Related Macular Degeneration and Population Attributable Risk for Variants at the Susceptibility Loci CFH, CFB, and LOC387715 in English Group 1.*

\begin{tabular}{lccc|}
\hline Locus (Variant) & \multicolumn{2}{c}{ Odds Ratio $(95 \%$ Cl) } & $\begin{array}{c}\text { Population } \\
\text { Attributable Risk }\end{array}$ \\
& Aa & aa & \\
CFH $($ Y402H) & & & $\%$ \\
CFB $(\mathrm{rs} 641153)$ & $3.1(2.0-4.6)$ & $6.3(3.8-10.4)$ & 63 \\
LOC387715 (rs10490924) & $2.4(1.6-3.6)$ & $2.4(1.5-3.8)$ & 43 \\
\hline
\end{tabular}

* Odds ratios are for the comparison with the AA genotype. "A" denotes common allele, and "a" minor allele.

bilize preformed immune complexes. The only significant difference was that C3F had lower activity than C3S in a hemolytic assay using sensitized sheep erythrocytes as a result of a small difference in cell-surface binding. Bartók and Walport ${ }^{28}$ found no differences between binding of C3S and C3F and the major complement receptor types 1,2 , and 3 .

On the other hand, there is compelling indirect evidence of a functional difference between C3S and C3F. A recent study has shown that the C3 S/F genotype is an important determinant of the long-term outcome of renal transplantation. ${ }^{29}$ In recipients who were C3S homozygotes, graft survival was substantially prolonged and renal function significantly better with $\mathrm{C} 3 \mathrm{~F} / \mathrm{F}$ and $\mathrm{C} 3$ F/S donor kidneys than with C3 S/S kidneys.

Several associations of disease with C3F have been reported, including IgA nephropathy, ${ }^{30}$ systemic vasculitis, ${ }^{31}$ partial lipodystrophy, and membranoproliferative glomerulonephritis type II (MPGNII). ${ }^{32,33}$ The association with MPGNII is particularly relevant. This is a rare disease characterized by complement-containing dense deposits in the glomerular basement membrane of the 


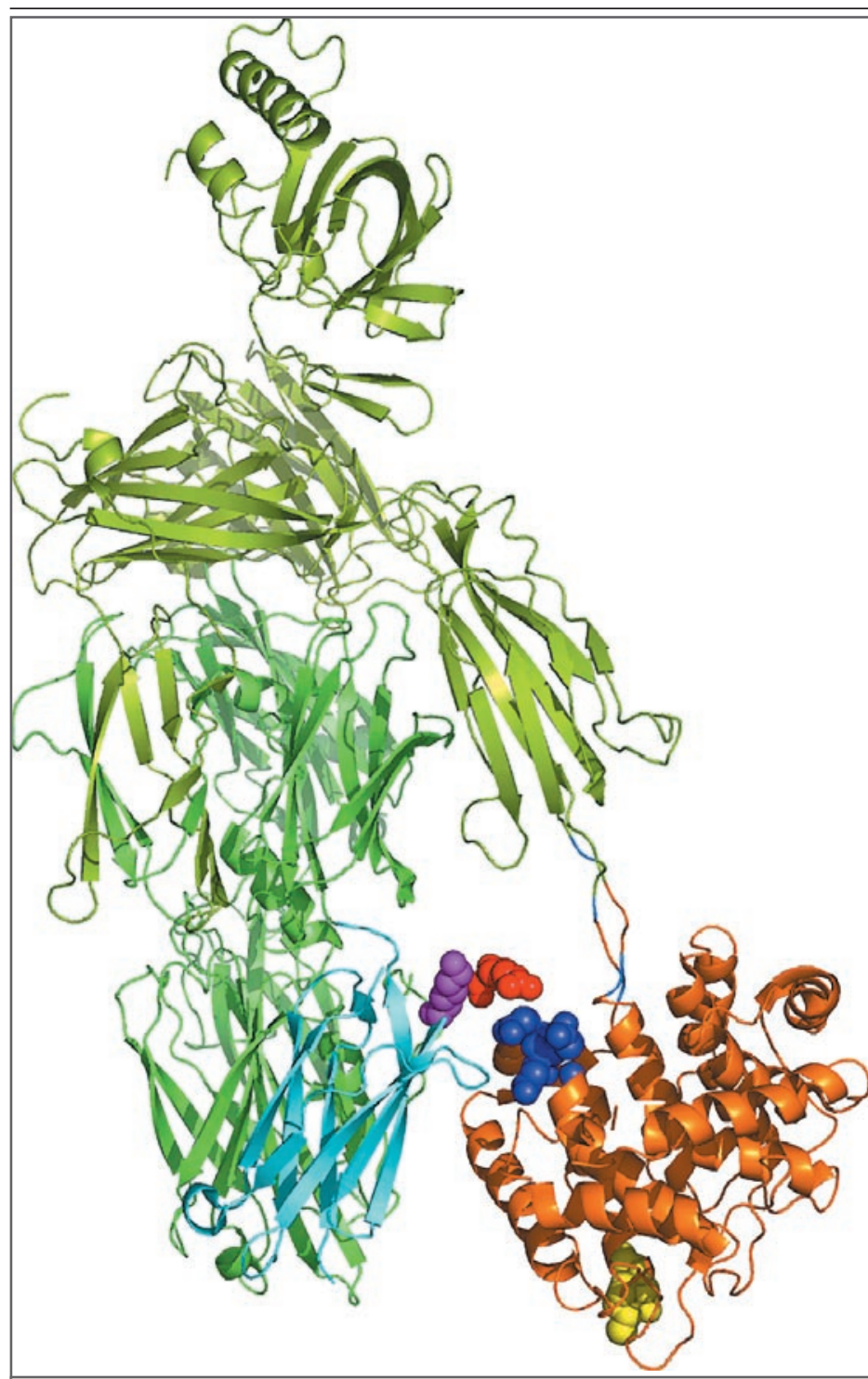

Figure 1. Structure of Complement C3b, Showing the Location of Arg80.

Ribbon representation of the structure of complement $\mathrm{C} 3 \mathrm{~b}$, as proposed by Janssen et al., ${ }^{24}$ shows the interface region between the macroglobulin 1 domain (MGl) (light blue) and the thioester-containing domain (orange). The residues participating in the formation of the thioester bond are shown in yellow. Arg80 (red) is located in MGl, adjacent to two other positively charged amino acids, Arg72 and Lys 82 (purple). These residues are approximately $4 \AA$ from the negatively charged amino acids Asp1007, Glu1008, Glu1010, and Glu1013 (dark blue) in the thioester-containing domain. The first three of these residues contribute to a probable $\mathrm{C} 3 \mathrm{~b} / \mathrm{C} 3 \mathrm{~d}$ binding site with complement factor $\mathrm{H} .{ }^{25} \mathrm{Arg} 80$ may also have interactions with negatively charged residues (not shown) in the complement $\mathrm{Clr} / \mathrm{Cls}-U$ egf$\mathrm{Bmpl-containing} \mathrm{domain,} \mathrm{adjacent} \mathrm{to} \mathrm{the} \mathrm{thioester-containing} \mathrm{domain.}$

kidney. ${ }^{34}$ The condition is caused by uncontrolled activation of the alternative complement pathway. In the majority of patients, the condition is associ- ated with serum $\mathrm{C} 3$ nephritic factor, ${ }^{34}$ an autoantibody directed against the $\mathrm{C} 3 \mathrm{bBb}$ complex, but rare cases associated with mutations in $\mathrm{CFH}$ have been reported. ${ }^{35} \mathrm{~A}$ similar form of glomerulonephritis develops in $\mathrm{CFH}$-deficient pigs $^{36}$ and $\mathrm{CFH}$ knockout mice. ${ }^{37}$ The interface of the capillary tuft, the glomerular basement membrane, and the glomerular epithelial cells in the kidney is similar in structure to the interface involving choriocapillaris, Bruch's membrane, and retinal pigment epithelium in the eye, and macular drusen similar to those in age-related macular degeneration develop in patients with MPGNII, but at a much younger age. ${ }^{38}$ These lesions are structurally and compositionally identical to those in patients with age-related macular degeneration and show immunoreactivity to complement $\mathrm{C} 5$ and C5b-9 complexes. ${ }^{39}$ Drusen have also been reported in patients with partial lipodystrophy. ${ }^{40}$ The association of MPGNII and partial lipodystrophy with C3F fits well with our current findings.

In summary, our study shows a strong association between the $\mathrm{C} 3 \mathrm{~F}$ variant and age-related macular degeneration, and there is evidence of functional differences between the C3 S/F allotypes. It follows that $\mathrm{C} 3 \mathrm{~F}$ is likely to have a causal role in the disorder. The estimated population attributable risk in the white population is $22 \%$. These findings add to our growing understanding of the genetics of age-related macular degeneration and provide conclusive evidence that the complement pathway has a key role in the pathogenesis of this common and debilitating condition.

Supported by grants from the Medical Research Council, United Kingdom (to Drs. Yates, Clayton, Bird, and Moore), the Chief Scientist Office, Scotland (to Dr. Dhillon), the Macular Vision Research Foundation (to Dr. Wright), and the Wellcome Trust and the Juvenile Diabetes Research Foundation (to Dr. Clayton). The Lothian Birth Cohort collection was supported by the Biotechnology and Biological Sciences Research Council. Dr. Deary is the recipient of a Royal Society-Wolfson Research Merit Award.

Dr. Dhillon reports receiving consulting fees from Novartis and Pfizer. No other potential conflict of interest relevant to this article was reported.

We thank members of the Scottish Macula Society Study Group (M. Gavin, F. Imrie, N. Lois, R. Murray, A. Purdie, A. Pyott, S. Roxburgh, C. Styles, M. Virdi, and W. Wykes) for their help in the recruitment of patients for our study; clinic staff and medical photographers at the participating clinics for their help; Tunde Peto and colleagues at the Reading Centre, Moorfields Eye Hospital, London, for grading the fundus photographs; the staff at Tepnel Life Sciences for performing the DNA extractions; Roger Williams for his helpful discussion about C3b protein structure; the International HapMap Consortium for the use of data; and all the patients and their families who participated in the study. 
APPENDIX

The following investigators are members of the Genetic Factors in Age-Related Macular Degeneration Study Group: S.S. Bhattacharya, P. Bishop, P. Black, Z. Butt, V. Chong, N.E. Day, C. Edelsten, A. Fitt, D.W. Flanagan, A. Glenn, S. Harding, C. Jakeman, C. Jones, R.J. Lamb, A. Lotery, V. Moffatt, C.M. Moorman, T. Peto, R.J. Pushpanathan, and T. Rimmer.

\section{REFERENCES}

1. de Jong PTMV. Age-related macular degeneration. N Engl J Med 2006;355:147485.

2. Haddad S, Chen CA, Santangelo SL, Seddon JM. The genetics of age-related macular degeneration: a review of progress to date. Surv Ophthalmol 2006;51:316-63. 3. Klein RJ, Zeiss C, Chew EY, et al. Complement factor $\mathrm{H}$ polymorphism in age-related macular degeneration. Science 2005;308:385-9.

4. Haines JL, Hauser MA, Schmidt S, et al. Complement factor $\mathrm{H}$ variant increases the risk of age-related macular degeneration. Science 2005;308:419-21.

5. Edwards AO, Ritter R III, Abel KJ, Manning A, Panhuysen C, Farrer LA. Complement factor $\mathrm{H}$ polymorphism and age-related macular degeneration. Science 2005;308:421-4.

6. Hageman GS, Anderson DH, Johnson $\mathrm{LV}$, et al. A common haplotype in the complement regulatory gene factor $\mathrm{H}$ (HF1 $\mathrm{CFH})$ predisposes individuals to age-related macular degeneration. Proc Natl Acad Sci U S A 2005;102:7227-32.

7. Sepp T, Khan JC, Thurlby DA, et al Complement factor $\mathrm{H}$ variant $\mathrm{Y} 402 \mathrm{H}$ is a major risk determinant for geographic atrophy and choroidal neovascularization in smokers and nonsmokers. Invest Ophthalmol Vis Sci 2006;47:536-40.

8. Li M, Atmaca-Sonmez P, Othman M et al. $\mathrm{CFH}$ haplotypes without the $\mathrm{Y} 402 \mathrm{H}$ coding variant show strong association with susceptibility to age-related macular degeneration. Nat Genet 2006;38:1049-54 9. Hughes AE, Orr N, Esfandiary H, DiazTorres M, Goodship T, Chakravarthy U. A common $\mathrm{CFH}$ haplotype, with deletion of CFHR1 and CFHR3, is associated with lower risk of age-related macular degeneration. Nat Genet 2006;38:1173-7. [Erratum, Nat Genet 2007;39:567.]

10. Gold B, Merriam JE, Zernant J, et al Variation in factor B (BF) and complement component 2 (C2) genes is associated with age-related macular degeneration. Nat Genet 2006;38:458-62.

11. Maller J, George S, Purcell S, et al. Common variation in three genes, including a noncoding variant in $\mathrm{CFH}$, strongly influences risk of age-related macular degeneration. Nat Genet 2006;38:1055-9.

12. Jakobsdottir J, Conley YP, Weeks DE, Mah TS, Ferrell RE, Gorin MB. Susceptibility genes for age-related maculopathy on chromosome 10q26. Am J Hum Genet 2005;77:389-407.

13. Dewan A, Liu M, Hartman S, et al HTRA1 promoter polymorphism in wet age-related macular degeneration. Science 2006;314:989-92
14. Yang Z, Camp NJ, Sun H, et al. A variant of the HTRA1 gene increases susceptibility to age-related macular degeneration. Science 2006;314:992-3.

15. Mullins RF, Russell SR, Anderson DH, Hageman GS. Drusen associated with aging and age-related macular degeneration contain proteins common to extracellular deposits associated with atherosclerosis, elastosis, amyloidosis, and dense deposit disease. FASEB J 2000;14:835-46.

16. Deary IJ, Whiteman MC, Starr JM, Whalley LJ, Fox HC. The impact of childhood intelligence on later life: following up the Scottish mental surveys of 1932 and 1947. J Pers Soc Psychol 2004;86:130-47.

17. Bird AC, Bressler NM, Bressler SB, et al. An international classification and grading system for age-related maculopathy and age-related macular degeneration. Surv Ophthalmol 1995;39:367-74

18. The International HapMap Consortium. The International HapMap Project. Nature 2003;426:789-96.

19. Azen EA, Smithies O. Genetic polymorphism of C'3(beta1C-globulin) in human serum. Science 1968;162:905-7.

20. Botto M, Fong KY, So AK, Koch C, Walport MJ. Molecular basis of polymorphisms of human complement component C3. J Exp Med 1990;172:1011-7.

21. Koch C, Behrendt N. A novel polymorphism of human complement component $\mathrm{C} 3$ detected by means of a monoclonal antibody. Immunogenetics 1986;23:322-5.

22. Walport MJ. Complement (first of two parts). N Engl J Med 2001;344:105866

23. Bora PS, Hu Z, Tezel TH, et al. Immunotherapy for choroidal neovascularization in a laser-induced mouse model simulating exudative (wet) macular degeneration. Proc Natl Acad Sci U S A 2003;100:2679-84

24. Janssen BJ, Christodoulidou A, McCarthy A, Lambris JD, Gros P. Structure of $\mathrm{C} 3 \mathrm{~b}$ reveals conformational changes that underlie complement activity. Nature 2006; 444:213-6

25. Jokiranta TS, Jaakola VP, Lehtinen MJ, Pärepalo M, Meri S, Goldman A. Structure of complement factor $\mathrm{H}$ carboxyl-terminus reveals molecular basis of atypical haemolytic uremic syndrome. EMBO J 2006;25:1784-94.

26. Arvilommi H. Capacity of complement c3 phenotypes to bind on to mononuclear cells in man. Nature 1974;251:740-1.

27. Welch TR, Beischel L, Kleesattel A. Functional consequences of the genetic polymorphism of the third component of complement. J Pediatr 1990;116:S92-S97. 28. Bartók I, Walport MJ. Comparison of the binding of $\mathrm{C} 3 \mathrm{~S}$ and $\mathrm{C} 3 \mathrm{~F}$ to complement receptors types 1,2 , and 3 . J Immunol 1995;154:5367-75.

29. Brown KM, Kondeatis E, Vaughan $\mathrm{RW}$, et al. Influence of donor C3 allotype on late renal-transplantation outcome. N Engl J Med 2006;354:2014-23.

30. Rambausek $M$, van den Wall Bake AW, Schumacher-Ach R, et al. Genetic polymorphism of C3 and Bf in IgA nephropathy. Nephrol Dial Transplant 1987;2: 208-11.

31. Finn JE, Zhang L, Agrawal S, Jayne DR, Oliveira DB, Mathieson PW. Molecular analysis of C3 allotypes in patients with systemic vasculitis. Nephrol Dial Transplant 1994;9:1564-7.

32. Finn JE, Mathieson PW. Molecular analysis of $\mathrm{C} 3$ allotypes in patients with nephritic factor. Clin Exp Immunol 1993; 91:410-4.

33. McLean RH, Winkelstein JA. Genetically determined variation in the complement system: relationship to disease. J Pediatr 1984;105:179-88.

34. Appel GB, Cook HT, Hageman G, et al. Membranoproliferative glomerulonephritis type II (dense deposit disease): an update. J Am Soc Nephrol 2005;16: 1392-403.

35. Abrera-Abeleda MA, Nishimura C, Smith JL, et al. Variations in the complement regulatory genes factor $\mathrm{H}(\mathrm{CFH})$ and factor $\mathrm{H}$ related 5 (CFHR5) are associated with membranoproliferative glomerulonephritis type II (dense deposit disease). J Med Genet 2006;43:582-9.

36. Hфgåsen $\mathrm{K}$, Jansen $\mathrm{JH}$, Mollnes TE, Hovdenes J, Harboe M. Hereditary porcine membranoproliferative glomerulonephritis type II is caused by factor $\mathrm{H}$ deficiency. J Clin Invest 1995;95:1054-61.

37. Pickering MC, Cook HT, Warren J, et al. Uncontrolled C3 activation causes membranoproliferative glomerulonephritis in mice deficient in complement factor $\mathrm{H}$. Nat Genet 2002;31:424-8.

38. Colville D, Guymer R, Sinclair RA, Savige J. Visual impairment caused by retinal abnormalities in mesangiocapillary (membranoproliferative) glomerulonephritis type II ("dense deposit disease"). Am J Kidney Dis 2003;42:E2-E5.

39. Mullins RF, Aptsiauri N, Hageman GS. Structure and composition of drusen associated with glomerulonephritis: implications for the role of complement activation in drusen biogenesis. Eye 2001;15: 390-5.

40. Patel D, Page B. Ocular complications in acquired partial lipodystrophy. Postgrad Med J 2006;82:774.

Copyright (c) 2007 Massachusetts Medical Society. 